SCIREA Journal of Clinical Medicine

ISSN: 2706-8870

http://www.scirea.org/journal/CM

May 31, 2021

Volume 6, Issue 3, June 2021

\title{
Dosimetric evaluation of the mean glandular dose for mammography in Indian (North East) women.
}

\author{
Jibon Sharma*, Gautam Goswami \\ State Cancer Institute, Gauhati Medical College. Guwahati, Assam, India \\ *Corresponding Author: Email: sharma5jibon@rediffmail.com
}

\begin{abstract}
The assessment of mean glandular dose is important to reduce and control the potential risk of radiation induced carcinogenesis during mammography procedure. The quantity which describes amount of risk for glandular tissue caused by application of radiation in mammography is called mean glandular dose (MGD). The purpose of the study was to estimate patient mean glandular doses in the two standard views, cranio-caudal and mediolateral oblique for mammography procedure. The study was also aimed to identify the various factors which influence the quantity MGD and Glandularity. Material and Methods: The following clinical data were collected from 72 numbers of women, who were referred to Radiology department, in a designed format during diagnostic examination:a) Patient demographic data like age, weight and height.b) Applied clinical spectrum (Target/filter combination.)c) Digital
\end{abstract}


readout of CBT (compressed breast thickness) and type of projection (CC, MLO) for each breast.d) Exposure factors: $\mathrm{mAS}$ and $\mathrm{kVp}$. The MGD per woman was calculated by summing the MGDs for all exposures and averaging it over both breasts. The MGD values are based on measurement of entrance surface air kerma (ESAK) and HVL.The measurements were done with Magic maxx mammography detector, IBA, using appropriate conversion coefficients as per IAEA protocol. For analysis of data Origin 2018b software was used for determining the descriptive and Pearson's correlation.Results: In this study, 72 women (18 to 78 years) were included. Mean age was $(42.28 \pm 14.8)$ years. The mean CBT value of $\mathrm{CC}$ view is $(4.04 \pm 1.13)$ c.m., which is lower than that of $(4.75 \pm 1.19)$ c.m. for MLO views. Significant difference was found between MGD from CC (1.10 $\pm 0.02 \mathrm{mGy})$ and MLO (1.26 $\pm 0.13 \mathrm{mGy})$ views. $(\mathrm{p}=0.0386)$. Significant relationships were seen between MGD per patient with respect to CBT $\left(\mathrm{R}^{2}=0.152, \mathrm{p}=0.0007\right), \mathrm{mAs}\left(\mathrm{R}^{2}=0.696, \mathrm{p}=0.00001\right)$ and glandularity $\left(\mathrm{R}^{2}=0.140, \mathrm{p}=0.0011\right)$.It was also noted that there was a considerable significance between glandularity and $\mathrm{CBT} \quad\left(\mathrm{R}^{2}=0.173, \mathrm{p}=0.00028\right)$.Discussion: The significant increase of doses in MLO in regard to $\mathrm{CC}$ projection can be explained with the fact that pectoral muscle is involved in MLO projection, which causes an increase of thickness of compressed tissue and require a greater dose for an image of a better quality. It is known that compressed breast thickness value shows a certain tendency of growth in younger patient and a tendency of decline in older patients, it was proved as true in our study and the similar symmetry was noted in other works (Suad Kunosic et al, 2012).Conclusions: The total MGD value per woman is (2.36 \pm 0.22$) \mathrm{mGy}$, which is between the limiting value of the Institute of Physical sciences in Medicine (2.0 mGy) and American College of Radiology (3.0 mGy) recommendation. These ensure that the mammography procedure performed in our centre is capable of achieving acceptable dose level for patient safety. 
Keywords: Mammography, CBT, MGD, Glandularity.

\section{Introduction}

In any radiological imaging procedure, it is important that radiation dose should be as low as reasonably practicable while maintaining an adequate image quality. Mammography is the most effective and accurate method for early detection of breast cancer [1]. However, there is a small risk of radiation-induced carcinogenesis associated with the mammographic procedure. Therefore, the estimation of absorbed dose to the glandular tissue of the breast is an important part of the quality control of the mammographic examination,[2] and it has become a key parameter in the establishment of local, regional and national standards [3].Breast composition varies among women due to different proportions of glandular, fibrous, and adipose tissue. Breast tissue composition also changes with age due to an increase in the proportion of adipose tissue. Glandular and fibrous tissues are visualised in mammography as radio-opaque (white), whereas adipose tissues are observed as radio-lucent (dark). Therefore, for the same compressed breast thickness, a dense breast (having a higher proportion of glandular tissues) absorbs a higher amount of radiation than an adipose breast. [4]. Simplified breast model considering the composition of $50 \%$ adipose and $50 \%$ glandular tissue does not represent the actual, therefore it is necessary to correct the glandularity for individual breast. Mean Glandular dose in digital mammography crucially depends on the estimation of individual breast glandularity.[5]

It is generally accepted that the glandular tissue of breast is the most radiosensitive tissue [6]. Therefore, the mean glandular dose (MGD) is the most appropriate dosimetry quantity to predict the risk of radiation- induced carcinogenesis [6,7].Image quality and MGD are dependent on breast characteristics (glandularity and thickness), exposure factors (beam quality, exposure time and compression force), detector features and mammography system performance (automatic exposure control) and characteristics (geometry, focal spot size)[4].

The most frequently-used procedure in a routine mammography examination includes two images of each breast: craniocaudal (CC) and mediolateral oblique (MLO) [8].For the latter an angle of $45^{\circ}$ is usually suitable for the majority of patients in routine daily practice period $[9,10]$ Even if there is a visible anomaly in one breast, it is necessary to perform a diagnostic mammographic examination of both breasts and detect possible anomalies into details [11]. 
The primary objective of this study was to estimate glandular absorbed radiation doses for the two standard views-CC and MLO-and to evaluate the MGD per woman as a function of compressed breast thickness, body mass index, patient age and percentage of glandularity. The European protocol on dosimetry in mammography [12] recommended two sensitive age groups of patients for assessment of the radiation risk from MGD during screening programme: one (40-49) age group of younger patients and another (50-64) age group of older patients. In this study the patient were grouped in to four groups of different ages including both the sensitive age groups. The deviations of CBT (compressed breast thickness), BMI (body mass index), MGD and glandularity in these four groups are assessed and the correlation analysis between the MGD and glandularity with other affecting factors are also checked. In addition, this study compared the MGD with the international standard dose and some published values from other studies.

\section{Materials and Methods:}

Equipment: The Mammography unit used for this study is a Hologic made (model-M-IV series) system with dual targets (both Mo and $\mathrm{Rh}$ ) and selectable focal spot sizes of 0.1 and 0.3 millimetres. An ant scatter grid with a grid ratio of 5:1 was used with a nominal focus to film distance of $66 \mathrm{~cm}$.During the period of data collection an extensive quality assurance procedure were performed in the mammography unit. All mammography images are recorded in (Model-AGFA CRMM3) CR cassettes. The breast substitute material used for the study was an Artinis Mammography-Phantom, (PASMAM-1054). The IBA Magic-Max Universal photo-diode detector system version RQM was used for determining the MGD in this study. This system has an external dose probe which designed for determining the input dose to medium or phantom especially for Mammography. The back shielded detector does not respond to the backscatters. The detector's main part is a PIN semiconductor Silicon photo diode. The diode detects the X-rays and produces a current proportional to the intensity of the X-rays. The currents, and charge, produced by the photo diode were measured with an electrometer and the output values can be recorded as either air kerma or dose.

\section{Mean glandular dose (MGD):}

For every mammogram, MGD was defined based on conversion factors calculated by Dance et.al. (2000) [13] and a calculated K (entrance air kerma measured freely in air without backscatter), using the following relation: 


$$
\mathrm{MGD}=\text { K.g.c.s }
$$

The entrance surface air kerma $(\mathrm{K})$ is defined as the incident air kerma measured free in air without backscatter, and $\mathrm{g}, \mathrm{c}$ and $\mathrm{s}$ are Monte Carlo calculated conversion factors. The Conversion factor $g$ (as a function of HVL and thickness) is the incident air kerma $(\mathrm{K})$ to MGD factor for a breast of $50 \%$ glandularity. The c-factor corrects the differences in breast composition from $50 \%$ glandularity. The s-factor corrects the differences arising from the use of X-ray spectra generated by anode target/filter combinations other than Mo/Mo. All these three factors are taken from the Dance's study by Monte-Carlo method. [14]

The quantity K, which is defined as the interpolated incident air kerma in the breast entrance surface and is defined as

$$
\mathrm{K}=\Gamma_{\mathrm{FDD}}(\mathrm{kV})\left\{\frac{\mathrm{FDD}}{\mathrm{FFD}-\mathrm{sb}}\right\}^{2} \mathrm{mAs}
$$

Where $\Gamma_{\mathrm{FDD}}$ is the incident air kerma at the focus to detector distance (FDD) per unit of tube load, measured as $\mathrm{mGy} / \mathrm{mAs}$, and is obtained by placing the detector below the upper compression plate so that the top of chamber is aligned with top of phantom. FFD is the focus to film distance, sь is the compressed breast thickness and mAs are the X-ray tube load during a routine exposure.

\section{Half Value Layer:}

The measurement of the 'half value layer "were made following the procedure of using the detector placed in the X-ray beam in such a position that its centre laid on the axis from the tube focus to a reference point, which is $4 \mathrm{~cm}$ from the chest wall edge and centred with respect to the lateral direction [15].For measuring HVL high purity (99.9\%) aluminium (Al) foils were used. The Al foils (0.1-0.4 mm thick) were placed on the top of the compression plate approximately halfway between the tube focus and detector. The detector was positioned on the top of mammography table.

For measurement of HVL, at first tube potential $(\mathrm{kVp})$ and adequate mAs (100 mAs) were selected and then the detector was exposed directly. The filters were positioned on the compression device to intercept the whole radiation field. The same procedure was followed for each filter.

The HVL is then calculated by the following formula. 


$$
H V L=\frac{x_{1} \ln \left(\frac{2 y_{2}}{y_{0}}\right)-x_{2} \ln \left(\frac{2 y_{1}}{y_{0}}\right)}{\ln \left(\frac{y_{2}}{y_{1}}\right)}
$$

The direct exposure reading denoted as yo and the exposure reading after X-ray beam interact with $\mathrm{Al}$ filter with thickness of $\mathrm{x}_{1}$ and $\mathrm{x}_{2}$ are $\mathrm{y}_{1}$ and $\mathrm{y}_{2}$.

Patients: The following clinical data were collected from 72 women referred to the radiology department, during diagnostic examination:

1) Patient demographic data like age, weight, and height.

2) Applied clinical spectrum (Target/filter combination) applied for each mammogram.

3) Digital readout of CBT (compressed breast thickness) and type of projection (CC, MLO) for each breast. The compressed breast thickness was later confirmed with the ruler available in the CR (computed radiography) system.

4) Exposure factors: mAs and $\mathrm{kVp}$.

It must be noted that in this study the MGD per woman was the total MGD of two views of each breast.

To know the composition of individual breast, the BI-RADS (Breast Imaging Reporting and Data System) recommendations are used (ACR, 2013) so that the individual breasts are classified by the radiologist by assessing visually according to its ascribed glandularity.

It is to be mentioned that all the patients underwent an ultrasound breast examination followed by mammography before preparing the final report by radiologist.

\section{RESULTS}

In this study, 72 women (18 to 78 years) were included. Mean age was $(42.28 \pm 14.8)$ years. The mean CBT value of the CC view was $(4.04 \pm 1.13)$ c.m., which is lower than that of (4.75 \pm 1.19$)$ c.m. for MLO views. A significant difference was found between MGD from CC $(1.10 \pm 0.42 \mathrm{mGy})$ and MLO $(1.26 \pm 0.55 \mathrm{mGy})$ views $(\mathrm{P}=0.0386)$ for a single exposure. The summary of the radiological parameters used for this study is listed in Table 1. 
Table 1: Mean \pm SD and range of exposure factors used in this study.

\begin{tabular}{|c|c|c|c|c|}
\hline \multirow{2}{*}{ Projection } & \multicolumn{2}{|c|}{ KV } & \multicolumn{2}{c|}{ mAs } \\
& Mean \pm SD & Range & Mean \pm SD & Range \\
\cline { 2 - 5 } & $25.06 \pm 0.75$ & $23-27$ & $39.76 \pm 14.53$ & $16.4-92$ \\
\hline CC & $25.29 \pm 0.64$ & $24-28$ & $48.50 \pm 19.17$ & $25-133.8$ \\
\hline MLO & $25.05 \pm 0.66$ & $23-28$ & $87.51 \pm 34.1$ & $45-225.8$ \\
\hline ALL & & &
\end{tabular}

SD*-standard deviation

The summarised results of compressed breast thickness (CBT), body mass index (BMI), MGD and Glandularity are listed in Table 2.

Table 2: CBT, MGD and Glandularity of patients with two different projections (CC, MLO) including total for all age groups.

\begin{tabular}{|c|c|c|c|c|c|}
\hline $\begin{array}{l}\text { Age Group } \\
\text { (in years) }\end{array}$ & & $\begin{array}{c}\text { CBT } \\
(\mathrm{Mean} \pm \mathrm{SD})\end{array}$ & $\begin{array}{c}\text { BMI } \\
(\text { Mean } \pm \text { SD) }\end{array}$ & $\begin{array}{c}\text { MGD } \\
(\text { Mean } \pm \text { CI) }\end{array}$ & $\begin{array}{l}\text { Glandularity } \\
(\text { Mean } \pm \text { SD) }\end{array}$ \\
\hline All & $\begin{array}{c}\text { Total } \\
\text { CC } \\
\text { MLO }\end{array}$ & $\begin{array}{l}4.39 \pm 1.13 \\
4.04 \pm 1.13 \\
4.75 \pm 1.19\end{array}$ & $22.73 \pm 3.48$ & $\begin{array}{l}2.36 \pm 0.22 \\
1.10 \pm 0.02 \\
1.26 \pm 0.13\end{array}$ & $48.88 \pm 19.5$ \\
\hline $40>$ & $\begin{array}{l}\text { Total } \\
\text { CC } \\
\text { MLO }\end{array}$ & $\begin{array}{l}4.69 \pm 1.07 \\
4.32 \pm 1.12 \\
5.06 \pm 1.07\end{array}$ & $21 \pm 3.30$ & $\begin{array}{l}2.75 \\
1.25 \\
1.50\end{array}$ & $50.1 \pm 24.5$ \\
\hline $40-49$ & $\begin{array}{l}\text { Total } \\
\text { CC } \\
\text { MLO }\end{array}$ & $\begin{array}{l}4.88 \pm 0.87 \\
4.45 \pm 0.81 \\
5.31 \pm 1.02\end{array}$ & $23.35 \pm 2.35$ & $\begin{array}{l}2.26 \\
0.99 \\
1.16\end{array}$ & $50.23 \pm 11.3$ \\
\hline $50-64$ & $\begin{array}{c}\text { Total } \\
\text { CC } \\
\text { MLO }\end{array}$ & $\begin{array}{l}4.06 \pm 0.84 \\
3.80 \pm 0.91 \\
4.32 \pm 0.78\end{array}$ & $25.17 \pm 3.19$ & $\begin{array}{l}2.03 \\
0.98 \\
1.05\end{array}$ & $48.82 \pm 16.3$ \\
\hline $64<$ & Total & $2.63 \pm 0.59$ & $22.01 \pm 6.23$ & 1.58 & $39.71 \pm 8.38$ \\
\hline
\end{tabular}




\begin{tabular}{|c|c|c|c|c|c|}
\hline & CC & $2.35 \pm 0.56$ & & 0.75 & \\
& MLO & $2.90 \pm 0.71$ & & 0.83 & \\
\hline
\end{tabular}

SD*-Standard deviation

CI*- A 95\%confidence interval

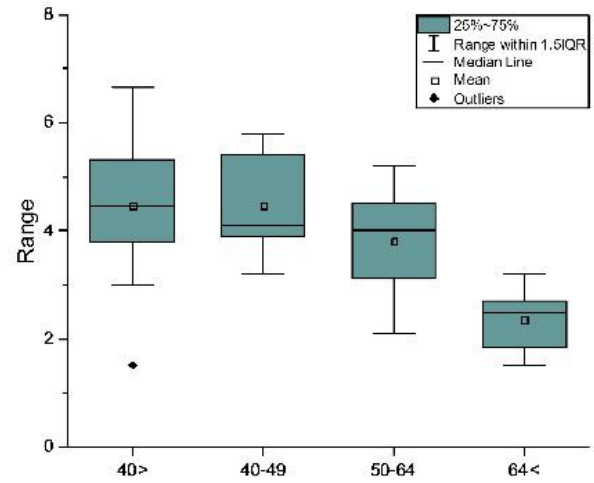

Fig 1(a): CBT

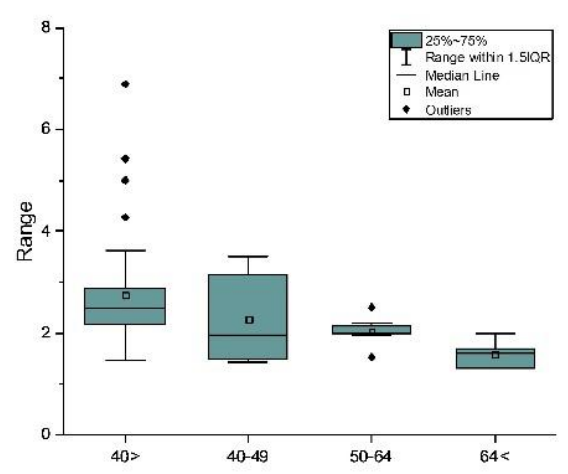

Fig 1(c): MGD

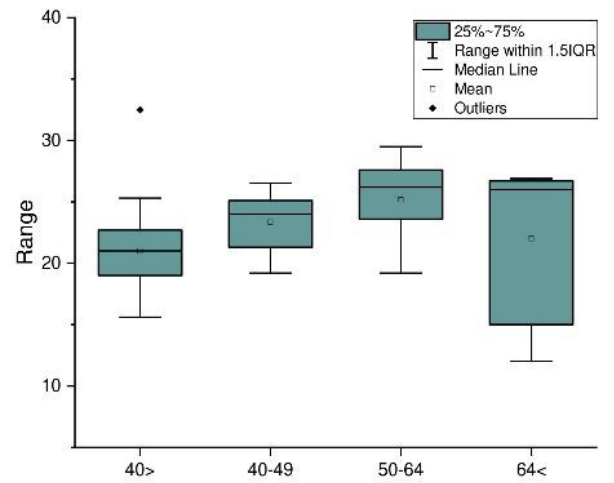

Fig 1(b): BMI

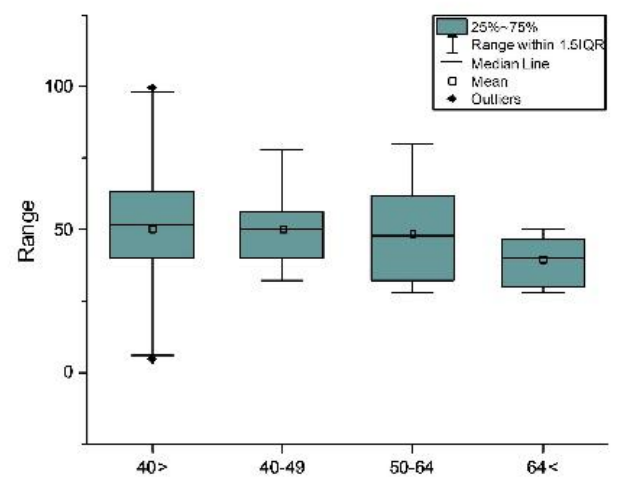

Fig 1(d): Glandularity

Figure-1(a), (b), (c) and (d) presents CBT, BMI, MGD and glandularity as a box \& whiskers plot calculated for different age groups. 


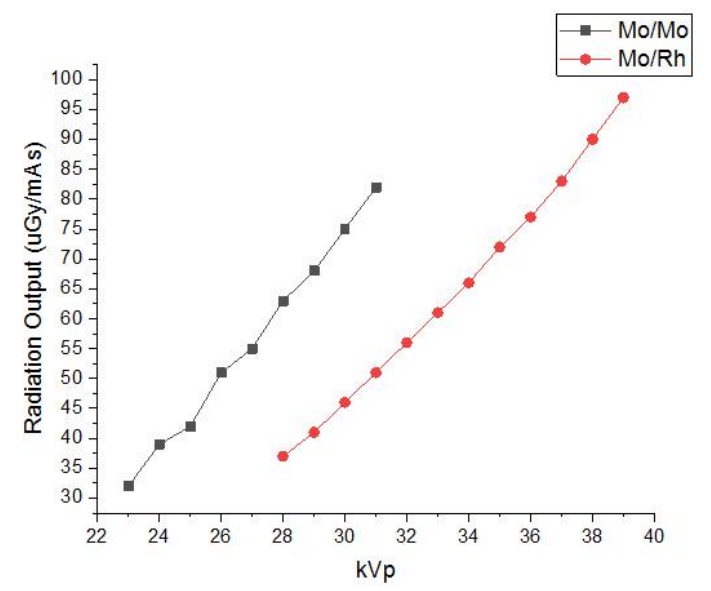

Figure-2: Radiation Output

Results of radiation output ( $\mu \mathrm{Gy} / \mathrm{mAs}$ ) measured at two different target/filter combinations (Mo/Mo and $\mathrm{Mo} / \mathrm{Rh}$ ) for various $\mathrm{kVp}$ (ranges from 23 to $39 \mathrm{kV}$ with $1 \mathrm{kV}$ step) are shown in Figure 2.The radiation output was measured five times for each $\mathrm{kVp}$ by the detector. During measurement, the machine is kept in automatic exposure control mode (Auto $\mathrm{kVp}$ ). In this study, auto-kVp was selected for all mammography examinations. Table-3 shows the results of comparison of different correlation analysis of the different age groups

Table 3: Result of correlation analysis between MGD and Glandularity with other affecting factors for all age groups.

\begin{tabular}{|c|c|c|c|c|}
\hline Factors & $\begin{array}{l}\text { Age group } \\
\text { (years) }\end{array}$ & $\begin{array}{l}\mathrm{R}^{2} \text { (Pearson } \\
\text { coefficient) }\end{array}$ & $\mathrm{P}$ & $\begin{array}{l}\text { Significant*/ } \\
\text { Not significant }\end{array}$ \\
\hline CBT vs. MGD & $\begin{array}{c}\text { All } \\
40> \\
40-49 \\
50-64 \\
64<\end{array}$ & $\begin{array}{l}0.152 \\
0.041 \\
0.544 \\
0.198 \\
0.132\end{array}$ & $\begin{array}{l}0.0007 \\
0.2450 \\
0.0017 \\
0.0956 \\
0.1710\end{array}$ & $\begin{array}{c}\text { Significant } \\
\text { Not significant } \\
\text { Significant } \\
\text { Not significant } \\
\text { Not significant }\end{array}$ \\
\hline BMI vs. MGD & $\begin{array}{c}\text { All } \\
40> \\
40-49 \\
50-64 \\
64<\end{array}$ & $\begin{array}{l}0.005 \\
0.154 \\
0.291 \\
0.344 \\
0.059\end{array}$ & $\begin{array}{l}0.5647 \\
0.0197 \\
0.0378 \\
0.0216 \\
0.5968\end{array}$ & $\begin{array}{c}\text { Not significant } \\
\text { Significant Significant } \\
\text { Significant } \\
\text { Not significant }\end{array}$ \\
\hline
\end{tabular}




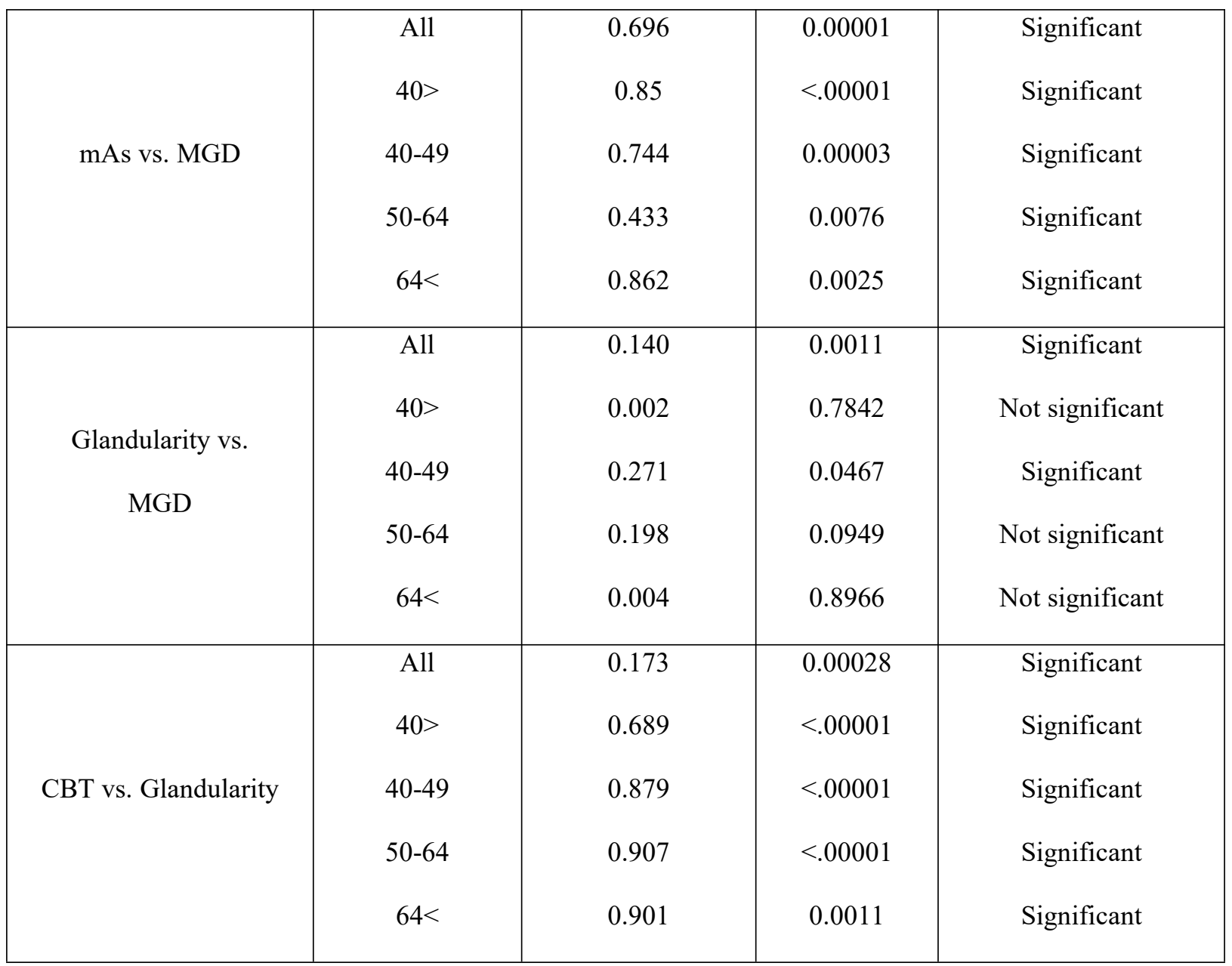

*significant for $\mathrm{P}<0.05$

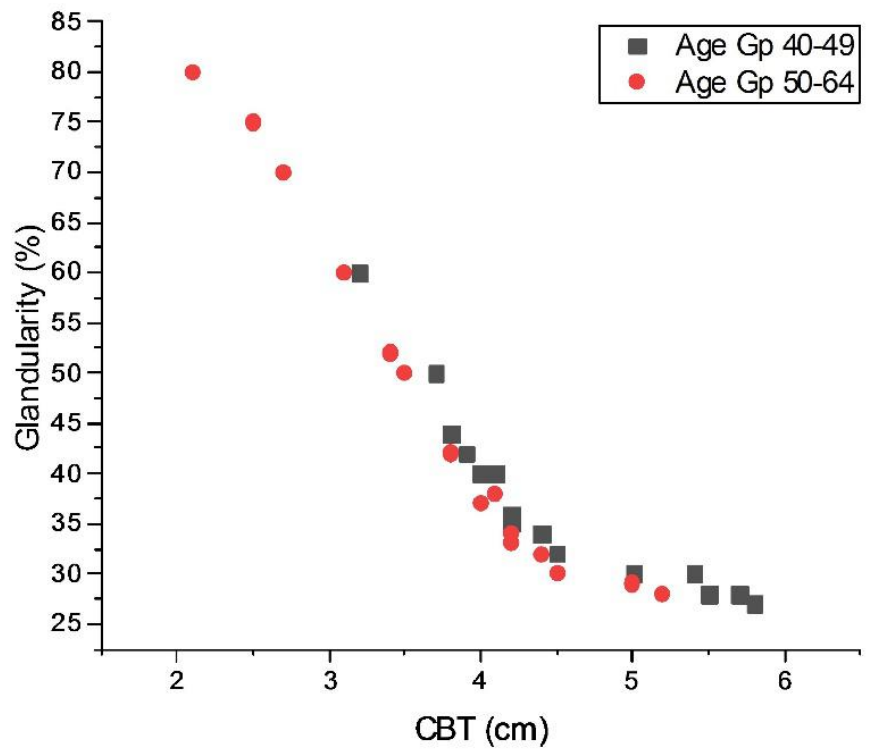

Fig-3: Glandularity for different CBT for two typical age groups 
In Fig.3 the glandularity as a function of breast thickness, grouped into two typical age categories, 40-49 years, and 50-64 years.

\section{DISCUSSION}

It is known that compressed breast thickness shows a slight tendency of growth in younger patients and a tendency of decline in older patients (as shown in Fig-1 a and table -2), this was supported in our study, and a similar trend was noted in other works. (Suad Kunosic et al, 2012) [19].

Regarding MGD, for different age groups it can be seen from the data in Fig-1(c) that the patient doses estimated for patient over 64 years were the lowest in comparison with other age group. Decrease of patient dose value with increasing of patient age due to change of BMI [fig- 1(b) and table-2] and breast glandularity [fig-1(c) and table-2] are notable in this study.

From the table 3 , it was found that for total patient of all age groups the factors CBT, mAs and glandularity are the factors which affect the MGD with considerable significance. $(\mathrm{P}<0.05)$. No significant relationship was observed between MGD per woman and BMI.In other way significant positive correlation were observed between CBT and Glandularity. To consider glandularity as a function of CBT, multiple linear regression was performed with glandularity as dependent and thickness as independent parameter. From the graph (fig -3) it was found that glandularity decrease both the age categories (40-49 yrs. and 50-64 yrs.) with the thickness without reaching saturation. Our results found good agreement with the studies by Salomon E.et al.[5]

The distribution (Fig-4) of CBT for both CC and MLO views show that there is a broad distribution in compressed breast thickness about $4.04 \mathrm{~cm}$ for CC views. The compressed thickness differs between CC \& MLO views. Mean MLO breast thickness is closer to $4.75 \mathrm{~cm}$. 


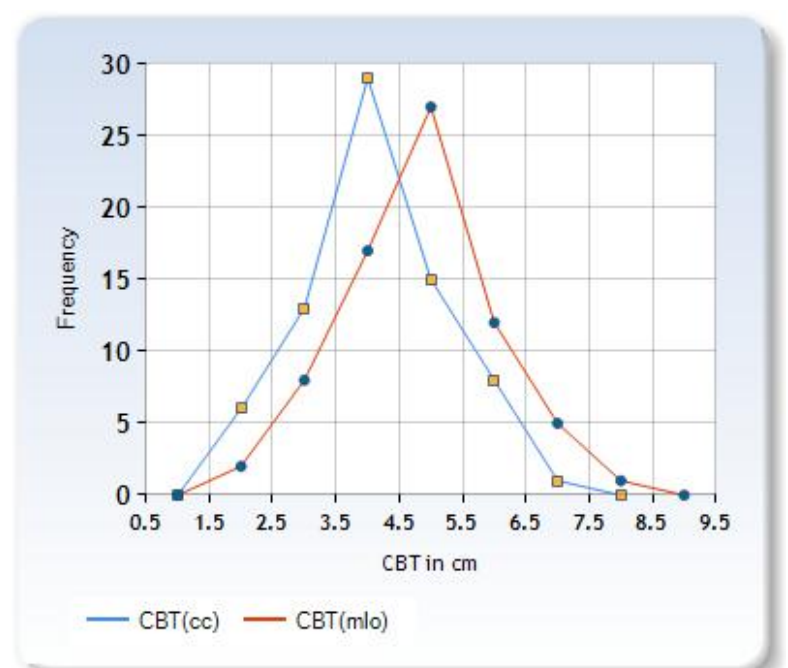

Figure-4: Distribution of Compressed breast Thickness.

The significant increase of doses in MLO compared with CC projection can be explained with the fact that pectoral muscle is involved in MLO projections, which causes an increase of thickness of compressed tissue and require a greater dose for an image of equal quality.

The average glandular dose delivered by a single craniocaudal view of a $4.2-\mathrm{cm}$ thick, compressed breast consisting of 50\% glandular and 50\% adipose tissue must not exceed 0.3 $\operatorname{rad}(3.0$ milli-gray) for both screen-

film and full-field digital mammography $[15,16]$. Our study measured MGD values of 2.36 mGy on average, which satisfies the restriction. The average breast glandularity of the study sample was $45.33 \pm 12.16)$.

The concept of MGD relies on computer simulations relating incident air kerma to dose in glandular tissue. To perform these calculations, a breast model needs to be defined .[5] Based on this study a $4 \mathrm{~cm}$ thick( thickness of $4.5 \mathrm{~cm}$ breast is equivalent to $4 \mathrm{~cm}$ PMMA phantom) ,45\% glandular and 55\% adipose phantom would be more representative of this population.

Table-4 compares the MGD values obtained in this work with published values from other studies. The value in the present study was found to be within the acceptable limit. The published work listed in the table used conversion factors the same source (Dance, 2009) as in this study. 
Table 4: Comparison of MGD values (in mGy) found in this work with other published work found in the literature

\begin{tabular}{|c|c|c|c|c|}
\hline Author & Country & DR & CR & $\mathrm{SF}$ \\
\hline This work & India & - & 2.36 & - \\
\hline Xavier et al. (2017) [17] & Brazil & $(2.86-3.83)$ & 3.91 & 2.70 \\
\hline Kawaguchi et al. (2014) [18] & Japan & 2.08 & - & - \\
\hline K. Suad et al. (2012) [19] & Bosnia and & - & - & 3.44 \\
\hline Hendrick et al. (2010) [20] & Canada & $(1.70-2.50)$ & 2.10 & 2.50 \\
\hline Young et al. (2000) [21] & UK & & & 3.30 \\
\hline
\end{tabular}

The study has some limitation. The results found may be biased since the data were collected from only one centre. A multi-centre study would be ideal for generalising our findings.

\section{CONCLUSION}

The total MGD value per woman is $(2.36 \pm 0.26) \mathrm{mGy}$, which is between the limiting value of the Institute of Physical sciences in Medicine (2.0 mGy) and American College of Radiology (3.0 mGy) recommendation. Thus, the mammography procedure performed in our centre can achieve acceptable dose levels for patient safety. At present, in our centre, mammography is performed as part of the Medicare system only is referral of 'symptomatic' women to radiologists. It is generally found that many of these referrals are for minimal symptoms or have resulted through family history or anxiety. It was observed that the number of 
mammography exams performed has increased over last few years. A screening programme for truly asymptomatic women is expected to commence in the near future at our centre.

\section{REFERENCES}

[1] Tomal A, PolettiME, Caldas LVE.Evaluation of subject contrast and normalized average glandular dose by semi-analytical models. Appl.Radiat. Isot.,2010;68:755-59.

[2] Xiang D, Ningle Y, Yimei Z, Jin W. The relationship of the mean glandular dose with compressed breast thickness in mammography. Journal of Public Health and Engineering, 2017; 1(32):1-8.

[3] Dance DR, SkinnerCL, CarlssonGA, Breastdosimetry. Appl.Radiat. Isot.,1999;50:185203.

[4] Haus AG, Yaffe MJ, Feig SA, et al. Relationship between phantom failure rates and radiation dose in mammography accreditation. Med Phys 2001; 28:2297-2301.

[5] Salomon E, Homolka P, Semturs F, Figl M, Gruber M \&Hummel J. Comparison of a personalized breast dosimetry method with standard dosimetry protocols. Scientific Reports,2019;9:5866 (1-9) [http://doi.org/10.1038/s41598-019-42144-7.]

[6] Klein R, Aichinger H, Dierker J, Jansen JTM, Joit-Barfub S, Sabel M.Determination of average glandular dose with modern mammography units for two large groups of patients. Phys Med Biol, 1997; 42:651-71.

[7] Beckett JR, Kotre CJ, Dosimetric implications of age-related glandular changes in screening mammography. Phys Med Biol., 2000; 45:801-13.

[8] Eklund GW, Cardenosa W. The art of mammographic positioning. Radiol.Clin. North.Am, 1992; 30:21-53.

[9] Brnic Z, HebrangA. Breast compression and radiation dose in two different mammographic oblique projections: $45^{\circ}$ and $60^{\circ}$.Euro. J. Radial. 2001; 40:10-15.

[10] Bouzarjomehri F, MostaarA, GhasemiA, EhramposhMH, Khosravi H.J. Radiol.,2006;4(1):

[11] Hackshaw AK, WaldNJ, MichellMJ, FieldS, Wilson ARM.An investigation into why two-view Mammography is better than one view in Breast Cancer Screening. Clinical Radiology, 2000; 55(6):454-58.

[12] Pery N., BroedersM., C. De Wolf and Tomberg Commissions of the European Communities, European Guidelines for Quality Assurance in Mammography Screening Report EUR 14821, Luxemberg,2001. 
[13] Dance DR, SkinnerCL, YoungKC, Beckett JR and Kotre CJ. Additional factors for the estimation of mean glandular breast dose using the UK mammography \& dosimetry protocol. PhysMed Biol,2000;45:3225-40.

[14] Dance DR, YoungKC, Van Engen RE. Further factors for the estimation of mean glandular dose using the United Kingdom, European and IAEA breast dosimetry protocols. Phys Med Biol 2009; 54:4361-72.

[15] Food and Drug Administration. The Mammography Quality Standards Act Final Regulations and Additions to Policy Guidance.[Available at: http://www.fda.gov/Radiation

EmittingProducts/MammographyQualityStandardsActandProgram/DocumentArchives/uc m114207.htm. Accessed March 28, 2018.

[16] Hendrick RE, Bassett L, Botsco MA, et al. Mammography Quality Control Manual. Reston, V.: American College of Radiology; 1999.

[17] Xavier AC, Andrade MEA, Pinto BVCC, Barros VSM, et al. Research on Biomedical Engineering ,2017;33(2):138-143. [ http://dx.doi.org/10.1590/2446-4740.02117]

[18] Kawaguchi A, Matsuraga V, Otsuka T, Suzuki S. Patient investigation of average glandular dose and incident air kerma for digital mammography, Radiol.Phy.Tech.2014;7(1):102-108. [ [http://dx.doi.org/10.1007/s12194-013-029-9. PMid:24234736.]

[19] Suad Kunosic (2012). An analysis of application of Mean Glandular dose and factors in which it depends to patients of various age groups, Mammography-Recent advances, Dr. NachikoUchiyama (Ed)ISBN: 978-953-51-0285-4, Intech [http://www.intechopen.com/books/mammography.recentadvances/an-analysis-of application-of-mean-glandular-dose-and factors-on-which-it depends to patients-of-var.]

[20] Hendrick RE,Pisano ED,Averbukh A, Moran C,Berns EA et.al.Comparison of acquisition parameter and breast dose in digital mammography and screen film mammography in the American College of Radiology Imaging Network Digital Mammographic Imaging $\begin{array}{llll}\text { screening } \quad \text { AJial, } & \text { 2010; }\end{array}$ [http://dx.doi.org/10.2214/AJR.08.2004 .PMid:20093597.]

[21] Young KC, Burch A. Radiation dose received in the UK breast screening programme in 1997 and 1998.Br. J. Radiology.2000;73:278-287. 